\title{
Indigenous production and interregional exchange: late second-millennium BC bronzes from the Hanzhong basin, China
}

Kunlong Chen ${ }^{1, *}$, Jianjun Mei ${ }^{1,2}$, Thilo Rehren ${ }^{3} \&$ Congcang Zhao ${ }^{4}$

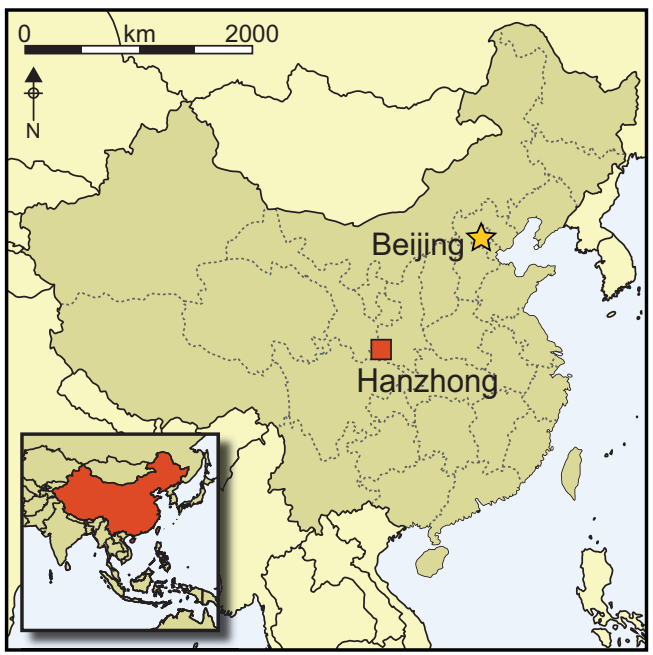

Traditional studies of early bronze metallurgy in China have focused on typology, decoration and production methods. The application of new analytical techniques to investigate chemical composition, however, is offering important new insights. The use of one such method (electron probe microanalysis) to study bronze artefacts from the Hanzhong basin in central China shows a level of diversity that implies much greater complexity in the extended landscape networks of the Bronze Age than was previously thought. The ability to appreciate these finds from a new perspective allows progression beyond older, simplistic models, and demonstrates that the Hanzhong region held greater importance within the power structure of Bronze Age Central China than has previously been recognised.

Keywords: China, Hanzhong basin, Bronze Age, metallurgy, landscapes, chemical composition analysis

\section{Introduction}

The emergence of copper metallurgy in China can generally be traced back to the late third and early second millennia BC in several regions, including the Northwest, the Northern Zone and the Central Plain (Mei 2009). Archaeological discoveries to date, however,

1 Institute of Historical Metallurgy and Materials, University of Science and Technology Beijing, 30 Xueyuan Road, Haidian District, 100083 Beijing, China

2 Needham Research Institute, 8 Sylvester Road, Cambridge CB3 9AF, UK

3 UCL Qatar, a partner of Hamad bin Khalifa University, PO Box 25256, Georgetown Building, Education City, Doha, Qatar

4 School of Cultural Heritage, Northwest University, 229 Taibaibeilu, 710069 Xi'an, China

* Author for correspondence (Email: kunlong.chen@ustb.edu.cn)

(C) Antiquity Publications Ltd, 2016. This is an Open Access article, distributed under the terms of the Creative Commons Attribution licence (http://creativecommons.org/licenses/by/4.0/), which permits unrestricted re-use, distribution, and reproduction in any medium, provided the original work is properly cited.

ANTIQUITY 90351 (2016): 665-678

doi:10.15184/aqy.2016.94 


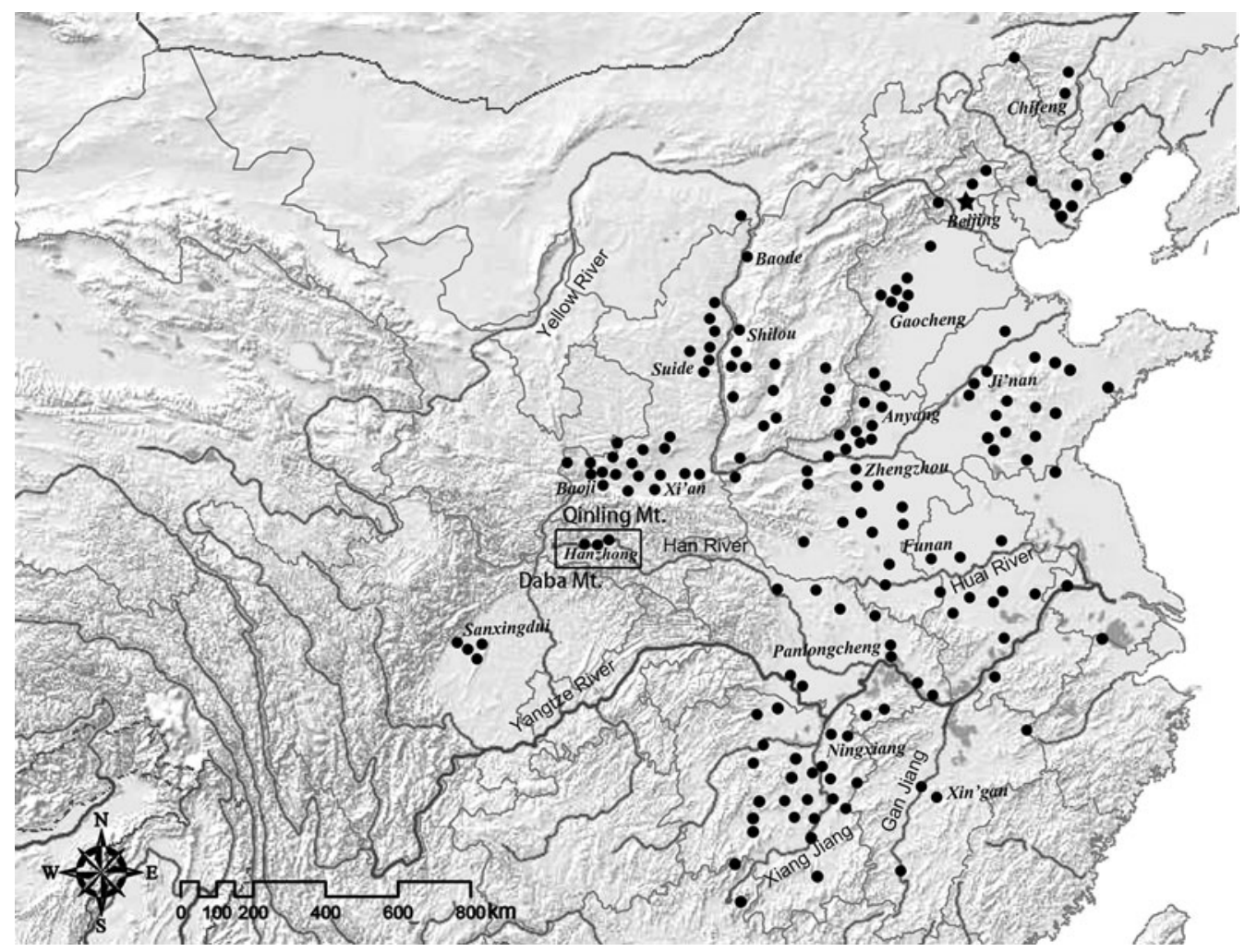

Figure 1. Distribution of the main sites yielding bronzes dating to the late second millennium BC in China, showing the location of Hanzhong and other sites mentioned in the text.

suggest that the widespread adoption of copper and bronze metallurgy in the territory of present-day China did not occur until the later part of the second millennium BC (Figure 1). The significant discoveries from the so-called 'peripheral areas' outside the core area of the Shang Kingdom in the Central Plain have given recognition to indigenous developments of bronze metallurgy in these areas, and stimulated substantial research interest among scholars both in China and abroad over the past decades (Kane 1974; Bagley 1977, 1990, 1993, 1999; B. Li 1990). While previous studies centred mainly on the typology, decorative styles and casting methods of the bronze objects, more recent attention has shifted to their scientific analysis in order to evaluate the technological similarity and diversity between the culturally different regions that produced them (Chen \& Mei 2006; Ma et al. 2012; Cui \& Wu 2013).

Among the so-called 'peripheral areas' outside the core area of the Shang Kingdom, the Hanzhong basin is undoubtedly one of the most intriguing. More than 700 bronze artefacts have been unearthed there since the 1950s, most of them dated to the late Shang period (fourteenth to eleventh centuries BC; Table 1). Earlier systematic examination of the Hanzhong bronzes has already revealed a number of the more significant technological characteristics of these bronzes (Chen et al. 2009; Mei et al. 2009). Examination of the Hanzhong bronzes from a wider cultural-technological perspective, however, has allowed

(C) Antiquity Publications Ltd, 2016 
Table 1. Chronology of the archaeological cultures discussed (in the region of the Middle Yellow River).

\begin{tabular}{ll}
\hline Time (BC) & Archaeological cultures (dynastic periods) \\
\hline $4000-3000$ & Yangshao \\
$3000-2600$ & Early Longshan \\
$2600-1900$ & Late Longshan \\
$1900-1600$ & Erlitou \\
$1600-1400$ & Erligang (Early Shang) \\
$1400-1300$ & Middle Shang \\
$1300-1046$ & Anyang/Yinxu (Late Shang) \\
$1046-771$ & Western Zhou \\
\hline
\end{tabular}

us to show that the Hanzhong region not only possessed its own indigenous metallurgical production, but also played an active role in interregional exchanges during the late Shang period. The results demonstrate that the development of metallurgical production in the late Shang period would be better framed within an exchange network of multiple regional centres, rather than an over-simplified core-periphery model.

\section{The Hanzhong bronzes and their technological characteristics}

The Hanzhong basin, situated in the south-western part of Shaanxi Province, is located on the upper reaches of the Han River and surrounded by the Qinling mountain range to the north and the Daba-Micang Mountains to the south (Figure 1). The basin has geographic connections reaching south-west to the Chengdu Plain, north to the Wei River valley and south to the Middle Yangtze region, making it an important centre for communication networks between different parts of China, a role that it has performed since the Neolithic Yangshao period (c. fifth to third millennia BC; SKY 1994).

Since the 1950s, dozens of ancient bronze hoards or caches have been found around the confluence of the Han and Xushui Rivers (Duan 1963; Tang et al. 1980; Chai et al. 2005), forming the Hanzhong bronze group, also known as the 'Chengyang bronze group', after the two counties of Chenggu and Yangxian in the eastern part of the basin (Zhao 1996). The total assemblage of Hanzhong bronzes, as counted in 2006, consists of more than 700 objects from 33 caches at 19 different sites (Figure 2). The group includes hundreds of weapons and 'Yang' discs (Figure 3: $12 \& 13$ ), dozens of ritual vessels, masks, 'Zhang' sceptres (Figure 3: $16 \& 17$ ), sickle-shaped objects (Figure 3: $18 \& 19$ ), and a few tools and ornaments (see online supplement 1 for a detailed list of the bronze caches and objects yielded) (Zhao 2006). The term 'Yang' discs refers to a group of pointed or perforated discs about $100 \mathrm{~mm}$ in diameter, which are considered by some scholars to have been used as bosses on shields (Huang \& Da 2007). A disc of a similar shape was unearthed at the Liulihe cemetery in Beijing, bearing an inscription indicating that it was named 'Yang' (Wang 2006; Cao 2011). The Zhang sceptres are blade-shaped objects with some decoration. Earlier examples of a 
Kunlong Chen et al.

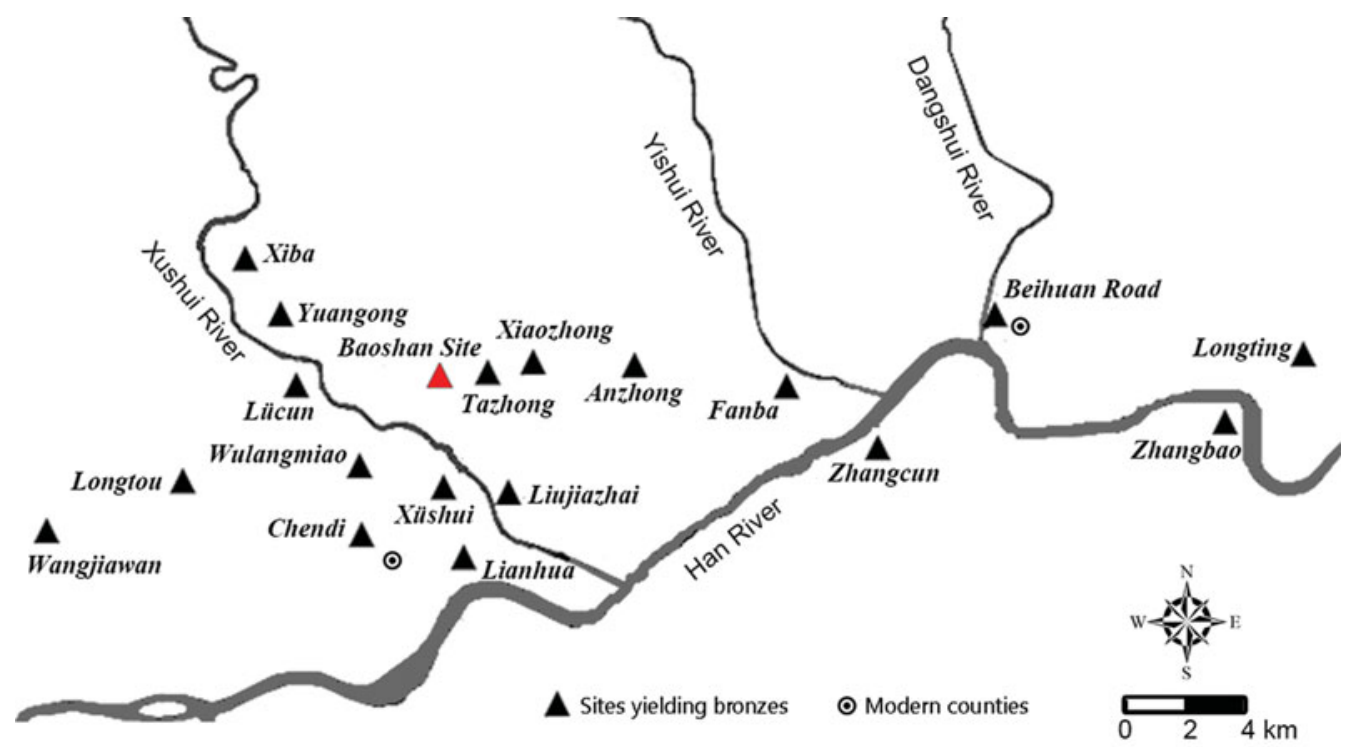

Figure 2. Map of the Hanzhong basin showing the distribution of bronze-deposition sites and the archaeologically excavated site at Baoshan (after Zhao 2006).

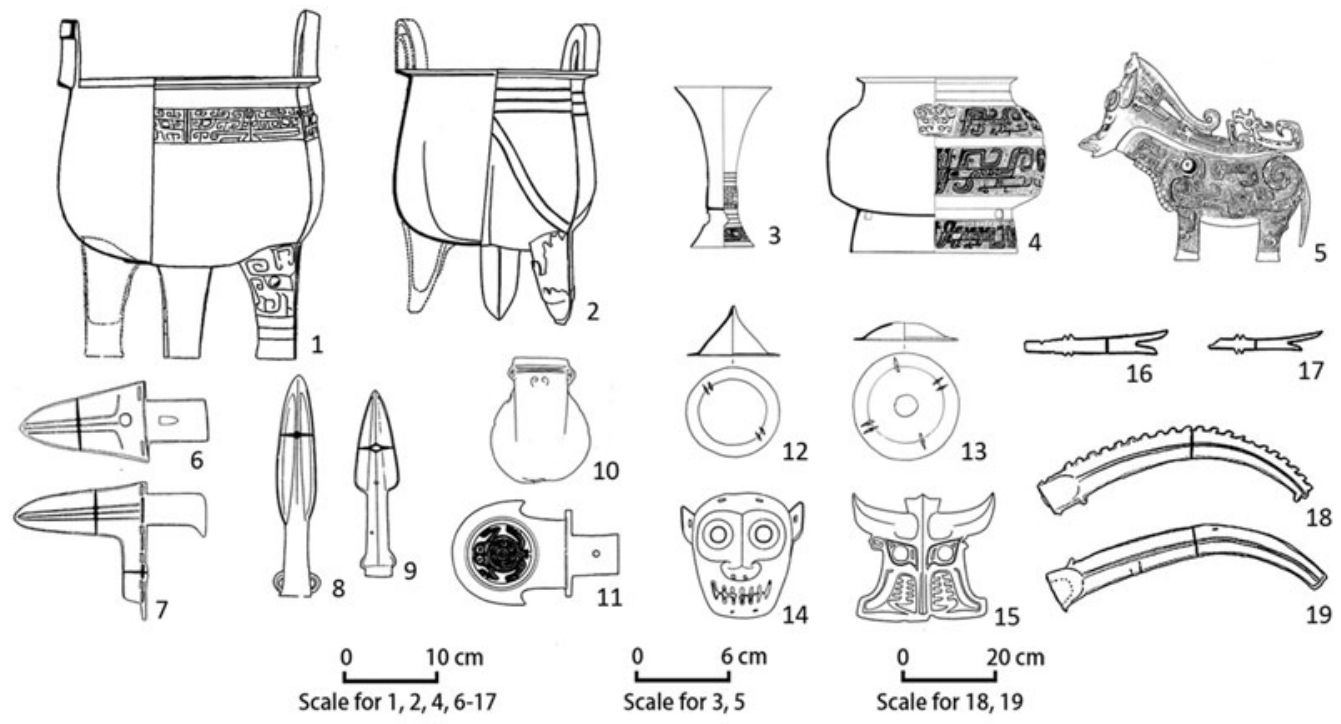

Figure 3. Different types of objects from Hanzhong (drawings after Cao 2006; Zhao 2006). 1) Ding tripod; 2) Li cauldron; 3) Gu goblet; 4) Bu jar; 5) Gong wine vessel; 6-7) Ge blades; 8-9) spear heads; 10) hole-handled Yue axe; 11) Yue axe; 12) Yang disc with projection; 13) Yang disc with central hole; 14) human-faced mask; 15) animal-faced mask; 16-17) Zhang sceptres; 18-19) sickle-shaped objects.

(C) Antiquity Publications Ltd, 2016 
similar shape were mostly made of jade or stone, and some scholars believe that they were used as ritual objects (X. Li 1992).

As a group, these bronzes, often found accidentally by farmers, have been assigned to the 'Baoshan Culture', which takes its name from the only extensively excavated site in the region, contemporary with the Shang culture of the Central Plain (XDWX 2002). Typological studies suggest an approximate date range from the Upper Erligang to the Late Anyang (Yinxu) periods, spanning the fourteenth to the eleventh centuries BC (Cao 2006; Zhao 2006), although some pieces in the group may date to the Western Zhou period (eleventh to eighth centuries BC) (C. Li 2007; von Falkenhausen 2011). The large number and great variety of objects (Figure 3) make the Hanzhong bronzes an outstanding example of the regional bronze cultures in the areas surrounding the core region of the Shang Kingdom, and have stimulated considerable research (B. Li 1983; Zhao 1996; X. Li 1997). While earlier studies concentrated on the Shang influences apparent in the Hanzhong bronzes, more recent work has put greater emphasis on its culturally mixed traits and connections with other contemporary bronze cultures (C. Li 2007; Bagley 2011; Rawson 2011; von Falkenhausen 2011). The existence of an indigenous metallurgical tradition in Hanzhong and its contribution to this group of bronzes, however, together with the dynamics of its interaction with other regions, remains uncertain and controversial.

Recent archaeometallurgical research has revealed important information that allows further analysis of the Hanzhong bronzes (Chen et al. 2009; Mei et al. 2009). More than 200 artefacts have been sampled for scientific analysis of their chemical composition and microstructure. They include 39 vessels, 54 weapons, 51 Yang discs, 19 masks, 31 sickle-shaped objects and 10 Zhang sceptres from 24 different caches, thus covering all the major types of this group of bronzes. Analysis by Electron Probe Microanalysis (EPMA) and Wavelength Dispersive Spectrometer (EPMA-WDS) was carried out in the Wolfson Archaeological Science Laboratories at the UCL Institute of Archaeology in London. A description of the analytical methods used and complete chemical composition data is presented in online supplement 2 .

Seven different materials have been identified among the objects analysed, namely: unalloyed copper ( $\mathrm{Cu}$ : 35 objects); tin bronze (Cu-Sn: 68); leaded tin bronze (Cu-Sn$\mathrm{Pb}: 81)$; leaded copper (Cu-Pb: 7); arsenical copper (Cu-As: 3); antimonial copper (Cu-Sb: 4); and copper-arsenic-nickel alloy (Cu-As-Ni: 6). It is not surprising that $\mathrm{Cu}-\mathrm{Sn}, \mathrm{Cu}-\mathrm{Pb}$ and $\mathrm{Cu}-\mathrm{Sn}-\mathrm{Pb}$ account for the majority (more than $75 \%$ ) of the objects analysed, reflecting the dominant role of the tin/lead bronze system in most contemporary Bronze Age cultures in China (Su et al. 1998; Han \& Ko 2007; Figure 4). A considerable proportion of unalloyed copper and the occurrence of rare alloys such as $\mathrm{Cu}-\mathrm{As}, \mathrm{Cu}-\mathrm{Sb}$ and $\mathrm{Cu}-\mathrm{As}-\mathrm{Ni}$, however, clearly demonstrate technological complexity and distinctiveness among the Hanzhong bronzes.

The results become more intriguing when plotted according to the different categories of object. The two most stylistically distinctive categories, sickle-shaped objects and Zhang sceptres, immediately stand out from the other artefact types (Figure 5). While notable portions of the vessel, weapon, Yang disc and mask categories were composed of tin/lead bronze, this was not used for sickle-shaped objects and Zhang sceptres, which were predominantly made of unalloyed copper and, less commonly, of what were probably 
Kunlong Chen et al.

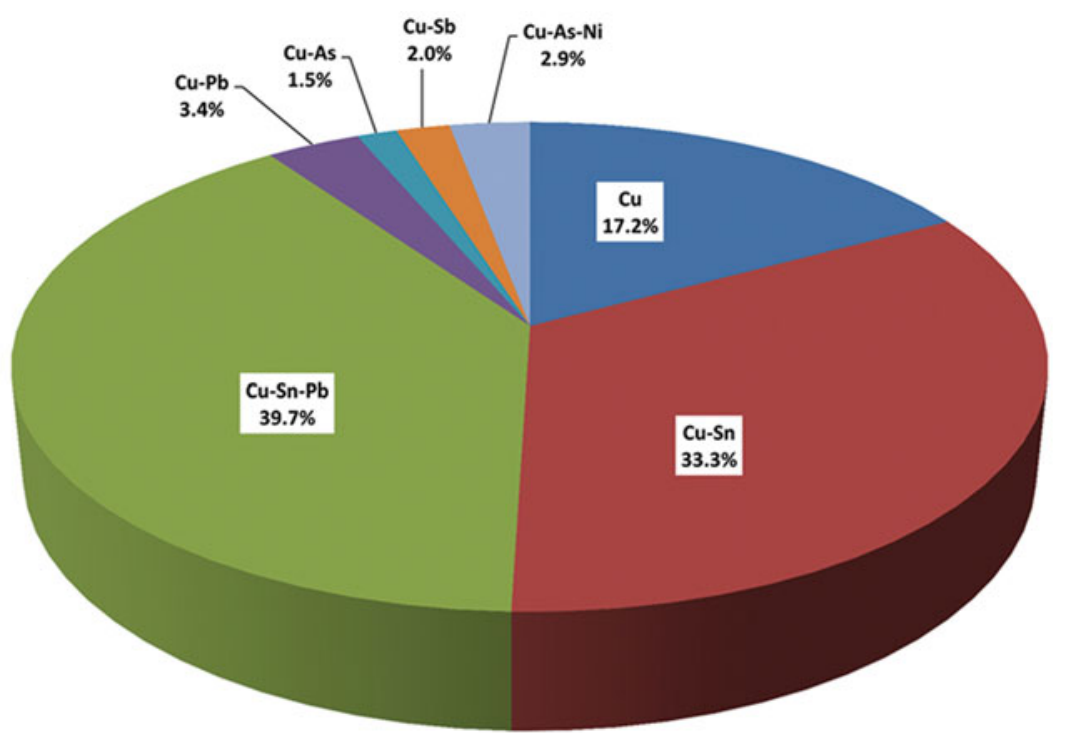

Figure 4. Proportional representation of material types among analysed objects.

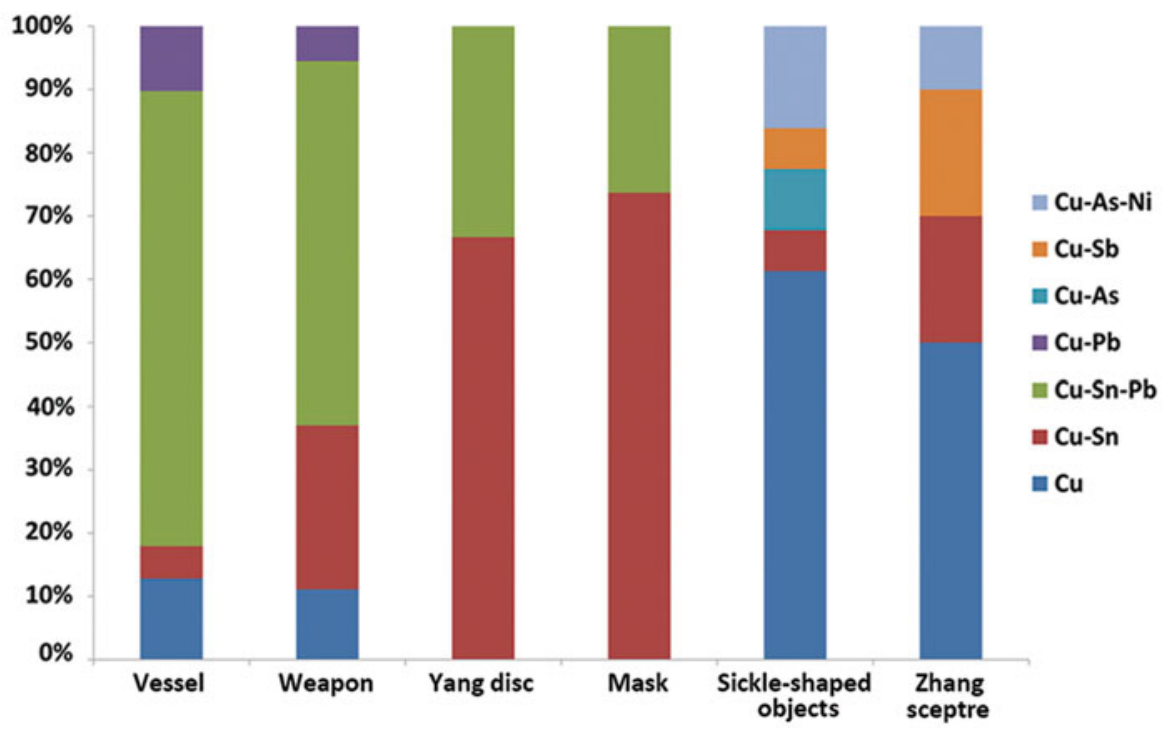

Figure 5. Material types of different object categories among the Hanzhong bronzes.

'natural' alloys ( $\mathrm{Cu}-\mathrm{As}, \mathrm{Cu}-\mathrm{Sb}$ and $\mathrm{Cu}-\mathrm{As}-\mathrm{Ni}$ ) that have not been identified in the other artefacts (Figure 5). Moreover, arsenic, antimony and nickel are frequently detected as minor/trace elements $(<2 \mathrm{wt} \%)$ in samples taken from sickle-shaped objects and Zhang sceptres, but they are much scarcer in other artefact categories (see online supplement 2).

(C) Antiquity Publications Ltd, 2016 
This suggests the presence of a local multi-metallic mineral source that could have been used to make the natural alloys.

The results of the analysis of the Hanzhong bronzes are highly significant for the study of bronze metallurgy in the Shang period. Never before has such a wide range of metals or alloys been documented in Shang-period metallurgy, nor has such a close match between specific artefact types and particular compositions been observed. More important still, the results revealed a distinct metal-using tradition, represented by the sickle-shaped objects and Zhang sceptres (Chen et al. 2009), that offers crucial scientific evidence for the existence of indigenous metallurgical production in Hanzhong, and for interaction between this centre and other regions.

\section{Indigenous metallurgical production in Hanzhong}

The sickle-shaped objects and the Zhang sceptres, which may have been used as insignia during ceremonial activities (X. Li 1997), are the most distinctive artefacts among the Hanzhong bronzes. Jade or stone Zhang sceptres were widely used as ritual objects in late Neolithic continental East Asia (X. Li 1992). During the Shang period, however, they seem to have been employed to a significant extent only in two regions: the Hanzhong basin and the Chengdu Plain (ZSKY 2003). Furthermore, it is only in Hanzhong that Zhang sceptres made of copper or bronze have been recovered in considerable numbers, while in the Chengdu Plain of Sichuan, only two miniature bronze Zhang sceptres have been reported so far (SWKY 1999; CWKY 2004). It is interesting to note that no items analogous to the Hanzhong sickle-shaped objects have been found anywhere else.

Further evidence for the existence of indigenous metallurgical production is provided by the discovery of three fragments of sickle-shaped objects during the excavation of the Baoshan site, the only archaeological site in the Hanzhong region dating to the late Shang period that has been properly excavated (XDWX 2002). Recent scientific examination of these pieces shows that two contain antimony (at the level of 4-6 wt\%), and one contains a small amount of arsenic (Chen et al. 2012a). This result is fully consistent with the compositional features of other sickle-shaped objects recovered in Hanzhong. The stylistic and chemical distinctness of sickle-shaped objects, as well as their direct association with the local archaeological culture, strongly imply that there must have been indigenous metallurgical production in the Hanzhong basin during the late centuries of the second millennium BC (Chen et al. 2009).

In the absence of direct archaeological evidence for the production process, many aspects of the local metalworking industry in Hanzhong are still unclear. The analytical data from bronze objects, however, provides, for the first time, an empirical criterion for identifying locally manufactured objects, namely the use of copper and natural copper-arsenic-antimony alloys instead of the leaded bronze prevalent in Shang metalwork. This is especially significant for a better understanding of the Hanzhong bronzes when we consider the complexity of the cultural traits revealed by previous stylistic studies (C. Li 2007; von Falkenhausen 2011). From their typological features, sickle-shaped objects, Zhang sceptres and socketed axes with blunt curved blades (Figure 3: 10,16-19) are most probably the product of local foundries 
in Hanzhong, while many other artefacts among the group of bronzes found in this region may have had their origins outside the Hanzhong basin.

\section{Hanzhong in a network of interregional exchange}

Many scholars have already observed that, among the Hanzhong finds, a number of ritual vessels of typical Shang style, and often of high quality, are a clear indication of the influence that Hanzhong received from the Shang metropolitan areas within a framework of 'core-periphery' interaction dynamics in Bronze Age China. Depending on their degree of similarity to Shang examples, bronzes recovered in Hanzhong, as with vessels from many other regions outside the Central Plain, have often been assigned ambiguous labels such as 'Shang-style', 'local' or 'hybrid' (B. Li 1983; Zhao 1996; Rawson 2011). These labels and their associated notions could be misleading, however, because they may oversimplify the complicated interaction network linking the many different regions. At the same time, the possible contribution of local metalworking, at least in the case of Hanzhong, may have been overestimated, as the term 'hybrid' often carries the implication that such pieces were made locally under the influence of another region. Yang discs and masks provide good examples of pieces that have been called 'local' or 'hybrid', but may not indeed have been made at Hanzhong.

It has been suggested that Yang discs and masks were most probably used as shield buckles or parts of armour (Wang 2006; Cao 2011). Many scholars tend to describe them as local Hanzhong products because of their remarkable stylistic characteristics and their occurrence in large numbers in that area (283 Yang discs and 48 masks) (Zhao 1996; Cao 2006; Wang 2006). Other opinions now suggest, however, that these unusual objects may have come from central Shaanxi, rather than being made locally, following the discovery of analogous pointed Yang discs at the Laoniupo site in central Shaanxi (Chen 2010; von Falkenhausen 2011). A connection between Hanzhong and the Guanzhong region in central Shaanxi is also supported by the results of our analysis. The Yang discs and masks, together with different types of 'Ge' (dagger-axe) from the same cache, are all made of remarkably high-quality (leaded) tin bronzes, which are easily distinguished from the products of local foundries (Figure 5). In addition to several almost identical Yang discs and masks, moulds for casting such objects have been excavated at the Laoniupo site in central Shaanxi (Figure 6; Liu 2002). As most of the Yang discs and masks were recovered from one single cache at Sucun Xiaozhong, it is reasonable to suggest that they were imported from central Shaanxi, rather than cast in the Hanzhong basin. Even though the assemblage at Sucun Xiaozhong probably dates to the Anyang period, based on stylistic grounds, the presence of several Erligang-style (c. 1600 to $1400 \mathrm{BC}$ ) tripod vessels among the Hanzhong bronzes suggests that the flow of bronzes from central Shaanxi to the Hanzhong basin might have started earlier (Chen et al. 2012b).

Hanzhong's connection with the Middle Yangtze River valley via the Hanshui River is also widely recognised by many scholars (Cao 2006; Bagley 2011; von Falkenhausen 2011). It has been suggested that high-quality bronze vessels of typical Erligang style found at Longtou may have been imported from Panlongcheng, a Shang offshoot site in Hubei in the Middle Yangtze valley (Figure 1). Vessels from the Longtou assemblage not only show

(C) Antiquity Publications Ltd, 2016 

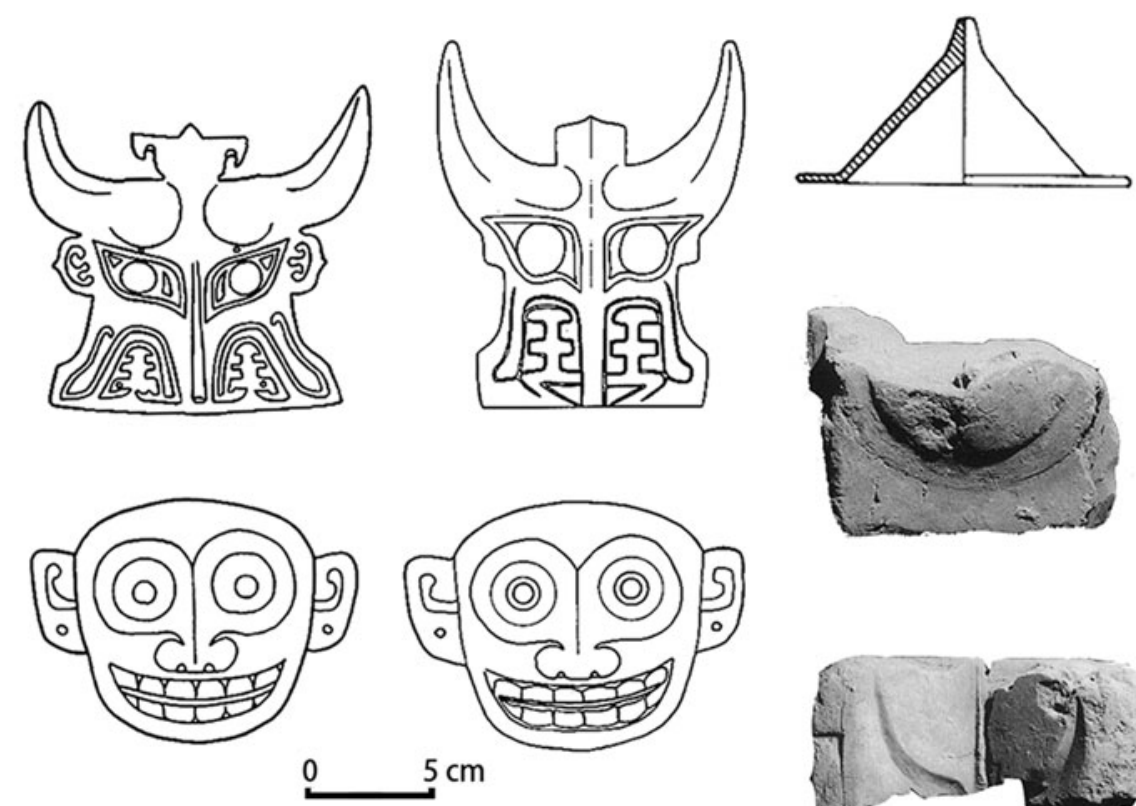

Figure 6. Bronze masks, Yang discs and moulds excavated from the Laoniupo site in central Shaanxi (after Liu 2002).

typological similarities with their counterparts at Panlongcheng, but some of them also exhibit exactly the same technical features. For example, bowl-shaped, ritual 'Gui' vessels from both Hanzhong and Panlongcheng both have cast-on handles; that is, the vessel bodies were made first and then the handles were cast onto them (Chen 2010). Although Panlongcheng was abandoned during the Anyang period with the decline of Shang power in the south, the connection between Hanzhong and the Yangtze region seems never to have been cut off. The presence of large, circular, shouldered vessels in Hanzhong is good evidence for this continuing connection between the two regions during the late Anyang period (Figure 7).

These large, circular, shouldered vessels, often called 'Zun' or 'Lei' and dated to the Anyang period, stand out among the Hanzhong bronzes because of their quantity and splendid decoration (Zhao 2006). They feature ornate high-relief decoration, jagged flanges and bands of whorl-shaped bosses, which are rather different from their counterparts in Anyang. During the 1970s and early 1980s, they were recognised as characteristics of independent southern bronze-manufacturing traditions in the Yangtze region, contemporaneous with the late Shang and Western Zhou periods in the Central Plain of China (Kane 1974; Gao 1981). Numerous new discoveries of similar vessels in Anhui, Hunan, Hubei and Jiangxi provinces provide further evidence to support the notion of one or more southern origins for these vessels. Several places in the Middle and Lower Yangtze River region have been suggested as their production centres (Rawson 1994; Shi 1998; Zhang 2004). It seems reasonable, therefore, to suggest that the large, circular, shouldered vessels recovered in the Hanzhong basin were imported from the Middle Yangtze River region via the Han River. It

(C) Antiquity Publications Ltd, 2016 


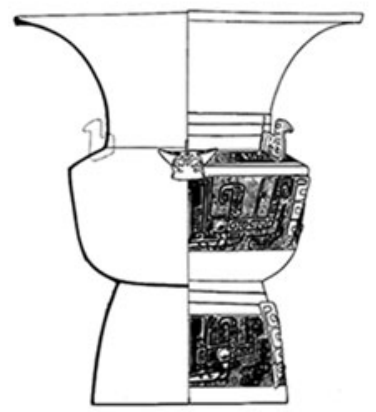

Hanzhong, Shaanxi

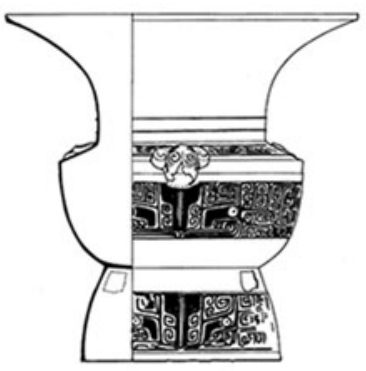

Hanzhong, Shaanxi

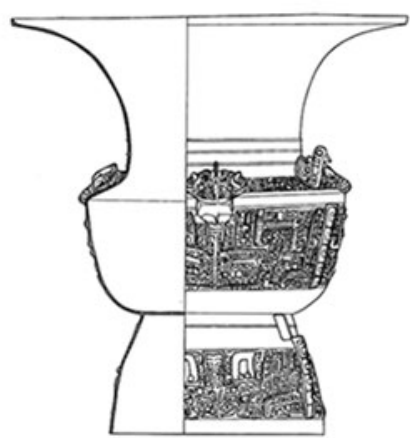

Sanxingdui, Sichuan

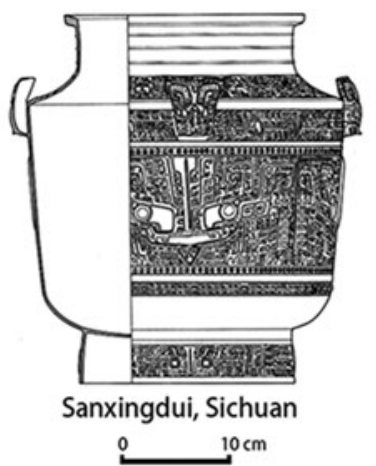

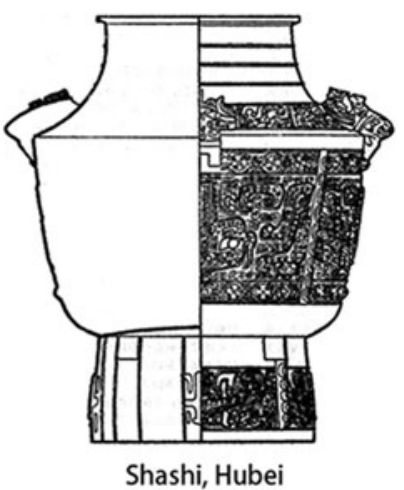

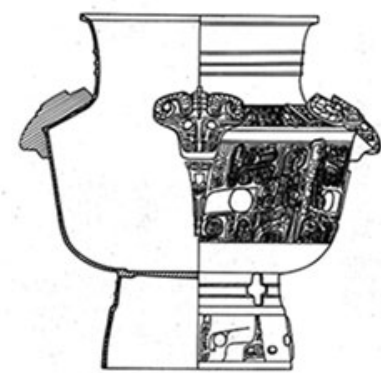

Dayangzhou, Jiangxi

Figure 7. 'Southern style' Zun and Lei vessels from Shaanxi, Hubei, Sanxingdui and Sichuan (after Jiangxi Museum 1997; SWKY 1999; Zhao 2006).

is of great interest to note that very similar large, circular, shouldered vessels, 'Zun', have also been found at the Sanxingdui site (Figure 1) in the Chengdu Plain, Sichuan Province (Jiang 2006; Zhang 2006). This strongly implies the existence of a network of regional exchanges, in which Hanzhong could have acted as a link between the Chengdu Plain and the Middle Yangtze River region, with the Han River as a crucial route of transportation.

\section{Beyond the 'core-periphery' model}

It has become increasingly clear that the most remarkable aspect of the Hanzhong bronzes is their diversity, in both typology and technology (C. Li 2007; Chen 2010; von Falkenhausen 2011). Even though the Hanzhong bronzes have generally been considered a single integral assemblage, they in fact comprise different groups of products from different regions. This observation leads to the recognition of multi-directional connections between the Hanzhong basin and many other regions, notably the Chengdu Plain in Sichuan to the south, the Guanzhong region in Shaanxi to the north and west, and the Middle Yangtze valley in Hubei and Hunan to the east and south-east. As many scholars have repeatedly pointed out, the presence of Erligang and Anyang bronzes among the Hanzhong bronze group would indicate contacts with the core areas of the Shang culture (B. Li 1990; Zhao (C) Antiquity Publications Ltd, 2016 
1996), but it is important to keep in mind that any influence from the core Shang areas would probably not have come to Hanzhong directly. Geographically contiguous regions in the Hubei and Shaanxi provinces would probably have acted as intermediaries for these contacts. More importantly, these regions would have made their own contribution to the Hanzhong region through these cultural exchanges (C. Li 2007; von Falkenhausen 2011). It seems, therefore, that Hanzhong acted as the nodal point of an exchange network during the Shang period. It was not a remote centre receiving cultural influence directly from the core areas of the Shang Kingdom, as a 'core-periphery' model might suggest.

Several major questions do, however, remain unanswered regarding the Hanzhong bronze group. Firstly, what was the purpose of the numerous caches and hoards, and can they tell us more about the nature of the contact that brought these bronzes to Hanzhong? One of the largest hoards, the Sucun Xiaozhong assemblage, consists almost exclusively of material that probably came from central Shaanxi to the north. This may indicate that, in this case, the bronzes were acquired in a single event, although that begs the question as to why such a quantity was imported. The social context behind these and other such movements of materials must also be considered. Another issue that requires thought is the manufacture of a small number of sickles and Zhang sceptres that appear to be made from tin bronze: were they made of imported Shang metals, such as bronze vessels looted or otherwise acquired, or were they made locally from materials with a different (arsenic-rich) trace element signature? Finally, interpretation must accommodate the lack of archaeological evidence for actual metallurgical sites. Even though we argue for the existence of indigenous metallurgical production in Hanzhong on the basis of the scientific evidence available so far, details of location and scale remain unknown. Consequently, this argument must remain a hypothesis until concrete evidence for actual metallurgical sites is found and confirmed in Hanzhong.

\section{Conclusions}

Recent technological studies show an unexpected complexity to the Hanzhong group of bronzes. Typologically unusual elements, such as the sickle-shaped objects and Zhang sceptres, have a very distinctive chemical composition. The close correlation between these stylistically local items and their unusual compositions, together with their close affiliation with the native Baoshan Culture, strongly implies that they were manufactured locally and that indigenous metallurgical production existed in the Hanzhong basin during the last centuries of the second millennium BC. By contrast, numerous other stylistically remarkable objects, namely the Yang discs and masks, have a different chemical composition, and may have been imported from production centres north of the Qinling Mountains, in central Shaanxi. Yet another group of artefacts, predominantly vessels of various styles, may have been linked to production centres in the Middle Yangtze region, which may have been under the direct control or influence of the Central Plain polity during the Erligang period but more probably enjoyed independence from Shang power during the Anyang period. Finally, among the Hanzhong bronzes are a number of ritual vessels that undoubtedly came from the Central Plain via central and eastern Shaanxi or the Hanshui River valley to the east. 
The most remarkable aspect of the Hanzhong group of bronzes is, therefore, their diversity and complexity in both typology and technology. The co-existence of objects of such diverse origins makes the group a unique cultural mixture. Given the relatively small proportion of locally made objects in the assemblage, the Hanzhong basin during the Bronze Age was more likely to have been a place where bronzes were imported and exchanged, rather than an important production centre for the manufacture of such a wide range of objects, including ritual vessels. Its special geographic position makes Hanzhong a pivotal crossroads, linking a number of regional centres between the Yellow River in the north and the Yangtze River in the south. It can be argued that the Hanzhong basin acted as a nodal point in an exchange network connecting different cultural groups.

The exchange network proposed in this study indicates the need to transcend the constraints of the overly simplistic 'core-periphery' paradigm. It also demonstrates the complexity of the metallurgical landscape during the late Shang period of the late second millennium $\mathrm{BC}$, which was characterised by the strong development of indigenous metallurgical centres in a number of regions, as well as by extensive interregional contacts and exchanges. In this landscape, individual regional bronze cultures were not simply all unilaterally linked to the Shang culture at the centre; instead, they had a considerable amount of interaction and exchange with each other. A new understanding of the Hanzhong bronzes not only places Hanzhong as one of several nodes in the exchange network, but also throws new light on the richness of bronze metallurgy in Bronze Age China.

\section{Acknowledgements}

The authors are grateful to Fulin Chai, Quntao Zhai and other scholars in Hanzhong for their support in the sampling and fieldwork necessary for this research project; and to Kevin Reeves at the UCL Institute of Archaeology for assisting with the EPMA analysis. Our thanks also go to Jessica Rawson (University of Oxford), Cao Wei (Museum of the First Emperor of Qin's Mausoleum Site), John Moffett (Needham Research Institute) and colleagues at the University of Science and Technology Beijing for their insightful comments, support and assistance. This work received research grants from the National Natural Science Foundation of China (51304020) and the National Administration for Cultural Heritage (2014220). Kunlong Chen gratefully acknowledges the support for his three research visits to London and Cambridge, provided, respectively, by the European Union under contract MEST2004-519504 for the Marie Curie EST Action Science and Conservation in Archaeology (2007), by the China Scholarship Council under a State Scholarship Fund (2007-2008), and by the Li Foundation of New York and the Chiang Ching-kuo Foundation for International Scholarly Exchange (2012-2013).

\section{Supplementary material}

Supplementary material for this article can be found at http://dx.doi.org/ 10.15184/aqy.2016.94

\section{References}

BAGLEY, R. 1977. Pan-lung-cheng: a Shang city in Hupei. Artibus Asiae 39: 165-219. http://dx.doi.org/10.2307/3250165

- 1990. A Shang city in Sichuan Province. Orientations 21(11): 52-67.

(C) Antiquity Publications Ltd, 2016
- 1993. An early Bronze Age tomb in Jiangxi Province. Orientations 24(7): 20-36.

- 1999. Shang archaeology, in M. Loewe \& E.L. Shaughnessy (ed.) The Cambridge history of ancient China: from the origins of civilization to 221 $B C$ : 124-231. Cambridge: Cambridge University Press. 


\section{Indigenous production and interregional exchange}

- 2011. A Zun from Yangxian, in W. Cao (ed.) Hanzhong chutu Shangdai qingtongqi [Shang Dynasty bronzes unearthed from Hanzhong], volume 4: 570-600. Chengdu: Bashu.

CAO, W. (ed.). 2006. Hanzhong chutu Shangdai qingtongqi [Shang Dynasty bronzes unearthed from Hanzhong], volume 1: 1-44. Chengdu: Bashu.

- 2011. Round-shaped dun yang of the Shang and Zhou Periods, in W. Cao (ed.) Hanzhong chutu Shangdai qingtongqi [Shang Dynasty bronzes unearthed from Hanzhong], volume 4: 311-31. Chengdu: Bashu.

Chai, F., T. He \& C. Gong. 2005. Shanxisheng Chengguxian xinchu shangdai tongqi [New discovery of Shang Dynasty bronzes from Chenggu County, Shaanxi Province]. Kaogu yu Wenwu 2005(6): 3-4.

CHen, K. 2010. Shanxi Hanzhong chutu shangdai tongqi de kexue fenxi yu zhizuo jishu yanjiu [Scientific study on the Shang Dynasty bronzes unearthed from Hanzhong, Shaanxi Province: materials and manufacturing techniques]. Unpublished PhD dissertation, University of Science and Technology Beijing.

Chen, K. \& J. MeI. 2006. Shanxi Lingshi Jingjie cun Shangmu chutu tongqi de kexue fenxi [Scientific analysis of bronzes from the Shang Dynasty tombs at Jingjie, Lingshi County, Shanxi Province], in Shanxi Provincial Institute of Archaeology (ed.) Lingshi Jingjie Shangmu [The Shang tombs at Jingjie, Lingshi]: 209-30. Beijing: Science.

Chen, K., Th. Rehren, J. Mei \& C. Zhao. 2009. Special alloys from remote frontiers of the Shang Kingdom: scientific study of the Hanzhong bronzes from southwest Shaanxi, China. Journal of Archaeological Science 36: 2108-18. http://dx.doi.org/10.1016/j.jas.2009.04.016

Chen, K., J. Mei \& C. Zhao. 2012a. Chenggu Baoshan yizhi chutu tongqi de kexue fenxi jiqi xiangguan wenwi [A scientific study on the copper and bronze artefacts unearthed from the Baoshan site, and its relevant issues]. Wenwu 2012(7): 85-92.

- 2012b. Lun Hanzhong chutu de Shangdai hongtong rongqi [Shang Dynasty red copper vessels unearthed in Hanzhong region]. Zhongguo guojia bowuguan guankan 2012(4): 132-38.

CuI, J. \& X. Wu. 2013. Sanxingdui yizhi jisiken zhong chutu bufen qingtong de jinshuxue he qian tongweisu bizhi zai fenxi [Metallurgical and lead isotope analysis of bronze wares unearthed from Sanxingdui site of sacrificial pits: some new insights on Sanxingdui Culture]. Nanfang Minzu Kaogu (2013)9: 237-50.
CWKY Chengdushi Wenwu Kaogu Yanjiusuo. 2004. Chendu Jinsha yizhi yiqu 'meiyuan' didian fajue yiqi jianbao [The first brief report on the excavation at locus Meiyuan in the Jinsha site, Chengdu City]. Wenwu 2004(4): 4-65.

DuAN, S. 1963. Jieshao Shanxisheng bowuguan de jijian qingtongqi [Introduction of several bronze objects of Shaanxi Provincial Museum]. Wenwu 1963(3): 43-44.

GAO, Z. 1981. 'Shang wenhua buguo Changjiang' bian [Debate on the argument of 'No Shang Culture in the south of Yangzi River']. Qiushi 1981(2): 107-12.

HaN, R. \& T. Ko. (ed.). 2007. Zhongguo kexue jishu shi kuangye juan [Volume of mining and metalwork, history of science and technology of China]. Beijing: Science.

HUANG, S. \& H. DA. 2007. Guanyu shangdai qingtong mianju de jige wenti [On the issues of Shang period bronze masks]. Jianghan Kaogu 2007(4): 47-52.

JIANG, Z. 2006. Sanxingdui xi qingtong rongqi chandi wenti [On the production origins of the bronzes vessels from Sanxingdui]. Sichuan Wenwu 2006(6): 30-36.

Jiangxi Museum. 1997. Xin'gan Shangdai Damu [A Shang period tome in Xin'gan County]. Beijing: Cultural Relics.

KanE, V.C. 1974. The independent bronze industries in the south of China contemporary with the Shang and Western Chou dynasties. Archives of Asian Art 28: 77-107.

LI, B. 1983. Chenggu tongqiqun yu zaoqi Shu wenhua [Bronzes unearthed from Chengu and their relationships with the ancient Shu Culture]. Kaogu yи Wenwu 1983(2): 66-71.

- 1990. Zhongguo qingtong wenhua de fazhan jieduan yu fenqu xitong [On the development phases and regional division of bronze cultures of China]. Huaxia Kaogu 1990(2): 82-91.

LI, C. 2007. Chenggu yangxian qingtongqi suohan zhouwenhua yinsu zhi wojian [Opinions on the bronzes unearthed from the Chenggu and Yangxian counties], in C. Li (ed.) Qintongqi xuebu ji [Collections of research papers on ancient bronzes]: 184-201. Beijing: Cultural Relics.

LI, X. 1992. Lun xianggang dawan xinchu yazhang ji youguan wenti [On the newly discovered Zhang sceptres from the Dawan site, Hong Kong, and related issues]. Nanfang Wenwu 1992(1): 18, 25-29.

- 1997. Lun Yangxian Fanba tong yazhang deng wenti [On the bronze sceptres unearthed from Fanba, Yanxian County and related issues]. Wenbo 1997(2): 13-14, 18. 


\section{Kunlong Chen et al.}

LIU, S. 2002. Laoniupo [Excavation report of the site of Laoniupo]. Xi'an: Shaanxi People's Publishing House.

Ma, J., Z. Jin, J. Tian \& D. Chen. 2012. Sanxingdui tongqi de hejin chengfen yu jinxiang yanjiu [A compositional and metallographic study of Sanxingdui copper objects]. Sichuan Wenwu 2012(2): 90-96.

MEI, J. 2009. Early metallurgy in China: some challenging issues in current studies, in J. Mei \& Th. Rehren (ed.) Metallurgy and civilisation: Eurasia and beyond: 9-16. London: Archetype.

MeI, J., K. CHEN \& W. CAO. 2009. Scientific examination of Shang-Dynasty bronzes from Hanzhong, Shaanxi Province, China. Journal of Archaeological Science 36: 1881-91. http://dx.doi.org/10.1016/j.jas.2009.04.017

RaWson, J. 1994. Contact between southern China and Henan during the Shang period. Transactions of the Oriental Ceramic Society 57: 1-24.

- 2011. Ornament and territory: the case of the bronzes from Hanzhong, in W. Cao (ed.) Hanzhong chutu Shangdai qingtongqi [Shang Dynasty bronzes unearthed from Hanzhong], volume 4: 341-61. Chengdu: Bashu.

SHI, J. 1998. Lun woguo chutu de Shangdai qingtong dakou Zun [On the Shang Dynasty wide flared mouth Zun vessel]. Wenwu 1998(10): 47-54.

SKY Shanxisheng Kaogu Yanjiusuo (ed.). 1994. Shannan kaogu baogao ji [Collections of archaeological reports of southern Shaanxi]. Xi'an: Sanqin.

SU, R., J. HUA, K. LI \& B. LU. 1998. Zhongguo shanggu jinshu jishu [Ancient metalwork technologies of China]. Ji'nan: Science and Technology Press of Shandong.

SWKY Sichuansheng Wenwu Kaogu Yanjiusuo. 1999. Shanxingdui jisi keng [Sacrificial pits excavated at Sanxingdui]. Beijing: Cultural Relics.
TANG, J., S. WANG \& C. GUO. 1980. Shanxisheng Chengguxian chutu yinshang qingtongqi zhengli jianbao [Brief report of the Shang Dynasty bronzes unearthed from the Chenggu County, Shaanxi Province]. Kaogu 1980(3): 211-18.

VON Falkenhausen, L. 2011. The Bronze Age in the upper Han River basin: some observations, in W. Cao (ed.) Hanzhong chutu Shangdai qingtongqi [Shang Dynasty bronzes unearthed from Hanzhong], volume 4: 378-516. Chengdu: Bashu.

WANG, Z. 2006. Chengyang tongqiyun zhong qingtongpao yongtu shitan, jianji renmianshi yu shoumianshi de yongtong [On the function of bronze Pao and masks unearthed from the Chenggu and Yangxian counties], in C. Zhao (ed.) Chengyang qingtongqi [Bronze objects unearthed from the Chenggu and Yangxian counties]: 281-302. Beijing: Science.

XDWX Xibei Daue Wenbo Xueyuan (ed.). 2002. Chenggu Baoshan: 1998 niandu fajue baogao [Excavation report of the Baoshan site in the Chenggu County in 1998]. Beijing: Cultural Relics.

ZHANG, C. 2004. Lun Yinxu shiqi nanfang de Zun he Lei [On the Zun and Lei vessels unearthed from southern China dating to Yinxu period]. Kaoguxue Jikan 2004(15): 116-28.

- 2006. Zichan yu shuru: cong wenshi fengge kan sanxingdui tongqiqun de butong chandi [Local production or imports: a discussion on the production origins of Sanxingdui bronzes based on the decoration styles]. Nanfang Wenwu 2006(3): 86-90.

ZHAO, C. 1996. Chenggu Yangxian tongqiqun zonghe yanjiu [A comprehensive study on the bronzes unearthed from the Chenggu and Yangxian counties]. Wenbo 1996(4): 3-26.

- (ed.). 2006. Chengyang qingtongqi [Bronze objects unearthed from the Chenggu and Yangxian counties]. Beijing: Science.

ZSKY Zhongguo Shehuikexueyuan Kaogu Yanjiusuo. 2003. Zhongguo kaoguxue Xia Shang Juan [Volume of Xia and Shang periods, Chinese archaeology]. Beijing: China Social Sciences.

Received: 26 April 2015; Accepted: 27 July 2015; Revised: 28 July 2015

(C) Antiquity Publications Ltd, 2016 